\title{
Sonic Boom and Drag Evaluation of Supersonic Jet Concepts
}

\author{
Yicheng Sun, ${ }^{1}$ and Howard Smith. ${ }^{2}$ \\ Cranfield University, Bedford, MK43 OAL, UK
}

\begin{abstract}
This paper evaluates three different class supersonic airliners (Concorde, Cranfield E-5, and NASA QueSST X-plane) in a multidisciplinary design analysis optimization (MDAO) environment in terms of their sonic boom intensities and aerodynamic performance. The aerodynamic analysis and sonic boom prediction methods are key to this research. The panel method PANAIR is integrated to perform automated aerodynamic analysis. The drag coefficient is corrected by the Harris wave drag formula and form factor method. For sonic boom prediction, the near-field pressure is predicted through the Whitham F-function method. The F-function is decomposed to the F-function due to volume and the F-function due to lift to see their individual effect on sonic boom. The near-field signature propagates in a stratified windy atmosphere using the waveform parameter method. The aerodynamic results are compared with experimental data and the sonic boom prediction results are validated by the NASA PCBoom program. Through the evaluation, we find a direct link between the wave drag and the first derivative of the volume distribution. The sonic boom intensity is influenced by the lift distribution and the volume change rate. The study helps to study the feasibility of low-boom and low-drag supersonic airliners.
\end{abstract}

\section{Nomenclature}

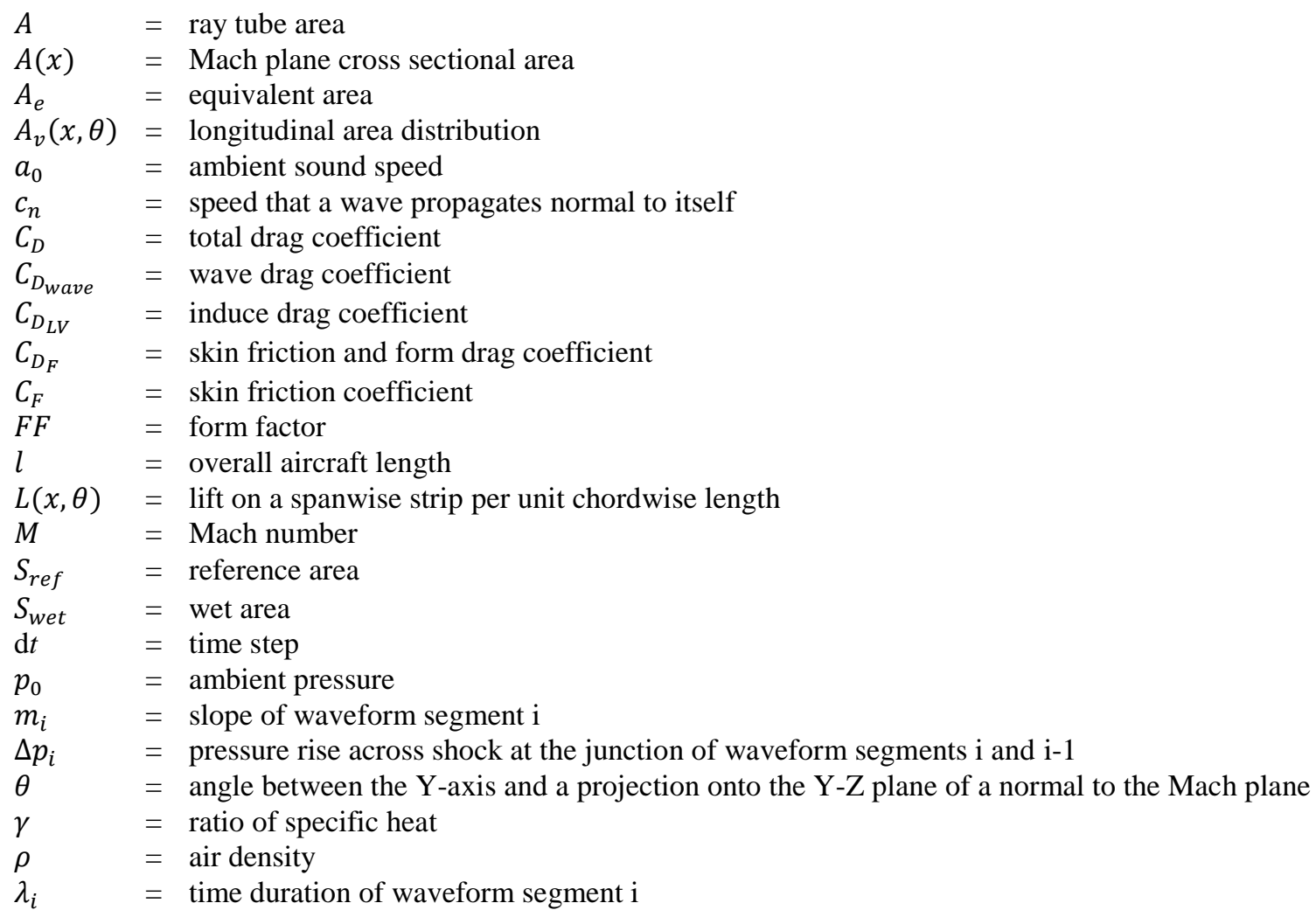

\footnotetext{
${ }^{1}$ Ph.D. student, School of Aerospace Transport and Manufacturing, AIAA Student Member.
}

${ }^{2}$ Professor, School of Aerospace Transport and Manufacturing, AIAA Senior Member 


\section{Introduction}

$\mathrm{T}$

HE supersonic business jet (SSBJ) is regarded as the pioneer of the next generation supersonic transport [1, 2].

The sonic boom is the biggest concern for the return of the civil supersonic transport. NASA is working on the Quiet Supersonic Technology (QueSST) X-plane to support the potential change in FAA regulations for supersonic flight over land. There are several SSBJ concepts proposed by different organizations and companies. There are also some supersonic business jet (SSBJ) concepts proposed by several commercial companies, the BOOM airliner, Spike S-512, HyperMach SonicStar, Aerion AS-2, SAI QSST-X, and so on. This paper evaluates three different classes of supersonic airliners (Concorde, Cranfield E-5 SSBJ, and NASA QueSST X-plane) with the aerodynamic analysis and sonic boom prediction methods developed in a multidisciplinary design analysis optimization (MDAO) environment called GENUS [3, 4].

There have been many studies on low-boom and low-drag supersonic business jets [5-13]. They, however, focused on a specific type configuration. There are also some qualitative studies on different SSBJ configurations [1, 2, 14-16]. This paper aims to evaluate the aerodynamics and sonic boom of different SSBJ configurations quantitatively and find out the most promising configuration for low-boom and low-drag supersonic airliner design.

In the following section, the supersonic aerodynamic analysis methods are introduced. Section IV gives a description of the near-field pressure calculation method. Section V describes the sonic boom propagation phenomenon and different boom propagation methods. Section VI gives the validation of aerodynamic analysis and sonic boom prediction methods. The SSBJ concepts are built and studied in an MDAO environment in section VI. The last section discusses the conclusions and future work.

\section{Aerodynamic Analysis}

The main aerodynamic analysis tool is PANAIR [17]. PANAIR is able to predict inviscid subsonic and supersonic flows of arbitrary configurations by solving a linear partial differential equation numerically. For aerodynamic analysis, PANAIR is able to provide lift coefficients and induced drag coefficients. The approach to integrating PANAIR into the MDAO environment for automated analysis is introduced in Ref. [3]. The drag components for supersonic flight consist of zero lift drag, wave drag, and induced drag, as accumulated in Eq. (1).

$$
C_{D}=C_{D_{F}}+C_{D_{\text {wave }}}+C_{D_{L V}}
$$

\section{A. Friction Drag}

The form factor method [18] is modified to calculate the zero-lift skin friction and form drag. The result comes from the contribution of each component, as shown in Eq. (2)

$$
C_{D_{F}}=\sum_{j=1}^{N} \frac{F F_{j} C_{F_{j}} S_{\text {wet }_{j}}}{S_{\text {ref }}}
$$

where $\mathrm{N}$ is the number of components used to model the configuration.

\section{B. Wave Drag due to Volume}

The supersonic area rule [19] is applied to calculate wave drag due to volume, as indicated in Eq. (3) and Eq. (4). For accurate wave drag calculation, the Mach plane cross sectional area intersecting with the geometry is required.

$$
\begin{gathered}
C_{D_{\text {wave }}}(\theta)=-\frac{1}{2 \pi} \int_{0}^{l} \int_{0}^{l} \mathrm{~A}^{\prime \prime}\left(x_{1}\right) \mathrm{A}^{\prime \prime}\left(x_{2}\right) \ln \left|x_{1}-x_{2}\right| \mathrm{d} x_{1} \mathrm{~d} x_{2} \\
C_{D_{\text {wave }}}=\frac{1}{2 \pi} \int_{0}^{2 \pi} C_{D_{\text {wave }}}(\theta) d \theta
\end{gathered}
$$

\section{Near-Field Pressure Prediction}

This section introduces the Whitham theory [20] used for the near-field pressure calculation. The equivalent area due to volume and equivalent area due to lift are required for the near-field pressure calculation.

A lower fidelity approach is to use the normal areas $A(x)$ for the equivalent area due to volume and use the wing platform area distribution $B(x)$ for the equivalent area due to lift. The total effective area $A_{e}(x)$ is obtained through Eq. (5). This approach is applied by the Carlson Simplified Sonic Boom Prediction method [21]. 


$$
A_{e}(x)=A(x)+B(x)=k_{1} x+k_{2} x^{2}
$$

The higher fidelity approach is to calculate the cross sectional areas on Mach planes. This is a complex calculation based on the parametric geometry module. The lift distribution comes from the PANAIR sectional properties, which give the lift coefficient on each cut. This approach is the basis of the waveform parametric method [22]. The equation for the total effective area calculation is indicated in Eq. (6).

$$
A_{e}(x, \theta)=A_{v}(x, \theta)+\frac{\beta}{2 q_{\infty}} \int_{0}^{x} L(x, \theta) d x
$$

The F-function derives from the equivalent area, as shown in Eq. (7).

$$
F(x)=\frac{1}{2 \pi} \int_{0}^{x} \frac{A_{e}^{\prime \prime}(\bar{x}, \theta)}{\sqrt{x-\bar{x}}} d \bar{x}
$$

In this study, we decompose the F-function to F-function due to volume and F-function due to lift, as indicated by Eq. (8). The purpose of this is to study their individual effects on sonic boom intensity.

$$
F(x, \theta)=F_{\text {volume }}(x, \theta)+F_{\text {lift }}(x, \theta)=\frac{1}{2 \pi} \int_{0}^{x} \frac{A_{v}^{\prime \prime}(\bar{x}, \theta)}{\sqrt{x-\bar{x}}} d \bar{x}+\frac{\beta}{4 \pi q_{\infty}} \int_{0}^{x} \frac{L^{\prime}(\bar{x}, \theta)}{\sqrt{x-\bar{x}}} d \bar{x}
$$

The near-field pressure is then calculated based on the Whitham theory, in Eq. (9).

where $\delta p=p-p_{0}$

$$
\delta p(x)=p_{0} \frac{\gamma M^{2} F(\chi)}{(2 \beta r)^{1 / 2}}
$$

$r$ is radial coordinate.

$\beta=\sqrt{M^{2}-1}$

$\chi=x-\beta r$ is the location on the axis of the equivalent body of the Mach plane translated field point.

\section{A. Area Distribution}

The area development comes from the parametric geometric model. Eq. (10) gives the Mach plane position $x_{i}$ at angle $\theta_{0}$. The Mach plane cross section distribution is illustrated in Fig. 1.

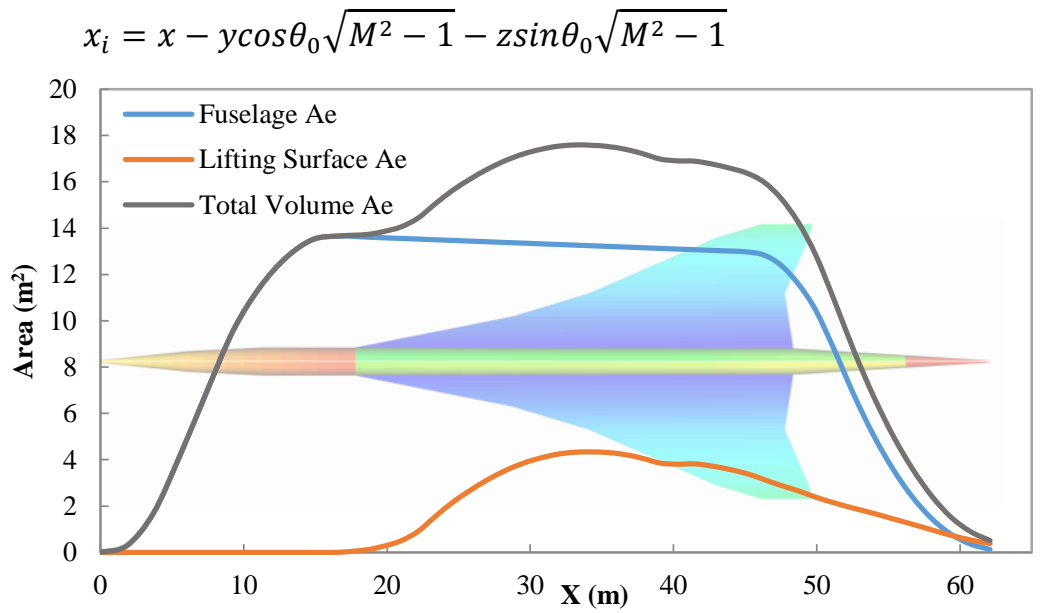

Fig. 1. Concorde Mach plane cross sectional area distributions

\section{B. Lift Distribution}

The lift development comes from the PANAIR program. The sectional property is utilised to get the lift distribution along the chordwise direction. An example of Concorde lift distribution is shown in Fig. 2. 


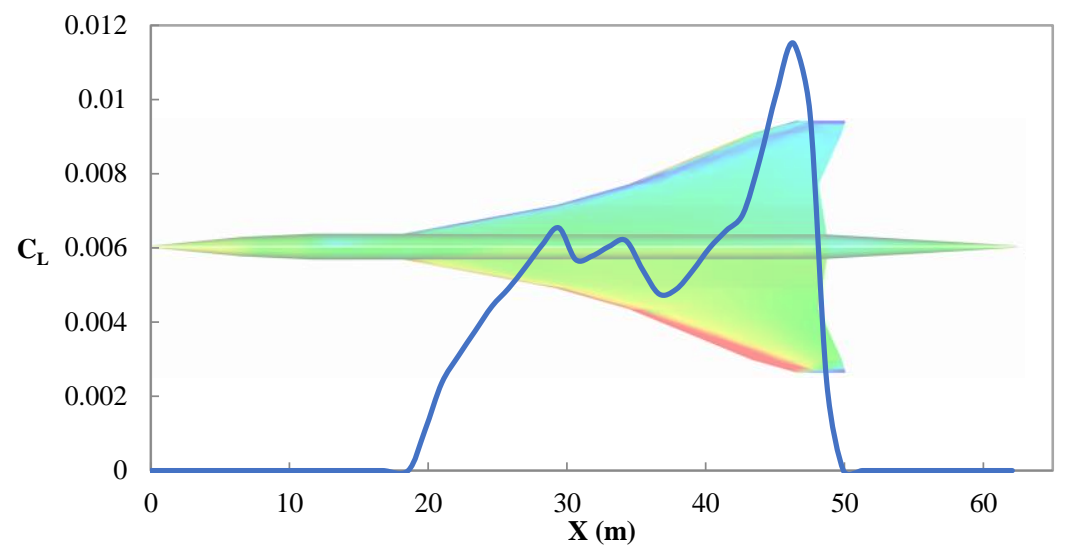

Fig. 2. Concorde chordwise lift distribution at cruise Mach 2.0

\section{Sonic Boom Propagation}

The sonic boom propagation methods include the Carlson simplified sonic boom prediction method [21] and the waveform parameter method [22]. The sonic boom signature propagates through the real stratified windy atmosphere is depicted in Fig. 3.

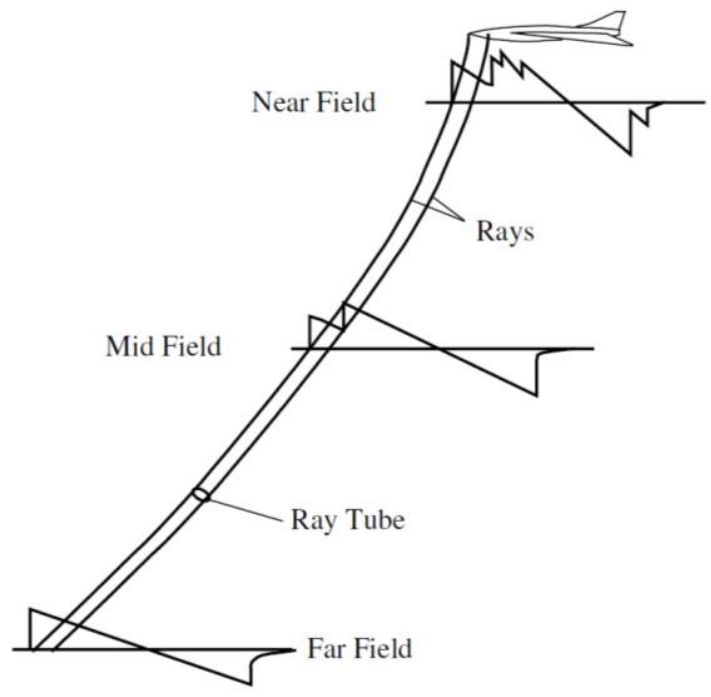

Fig. 3 Schematic of sonic boom propagation

\section{A. Simplified Sonic Boom Prediction Method}

The Simplified Sonic Boom Prediction method accounts for the atmospheric effect by defining the effective Mach number $M_{e}$ and effective altitude $h_{e}$. The total overpressure and signature duration on the ground are shown in Eq. (11)and Eq. (12). More details can be found in Ref. [21].

$$
\begin{gathered}
\Delta P_{\text {max }}=K_{P} K_{R} \sqrt{p_{v} p_{g}}\left(M^{2}-1\right)^{1 / 8} h_{e}^{-3 / 4} l^{3 / 4} K_{S} \\
\Delta t=K_{t} \frac{3.42}{a_{V}} \frac{M}{\left(M^{2}-1\right)^{3 / 8}} h_{e}{ }^{1 / 4} l^{3 / 4} K_{S}
\end{gathered}
$$

where $K_{P}$ is pressure amplification factor.

$K_{R}$ is reflection factor, assumed to be 2.0 .

$K_{S}$ is aircraft shape factor.

$K_{t}$ is signature duration factor.

$l$ is aircraft fuselage length. 


\section{B. Waveform Parameter Method}

Waveform parameter method [22] is based on geometrical acoustics. This method is more suitable for automatic computation. The waveform parameters $\mathrm{m}_{\mathrm{i}}, \Delta \mathrm{p}_{\mathrm{i}}$ and $\lambda_{\mathrm{i}}$ describe the near-field pressure linear segments, as shown in Fig. 4.

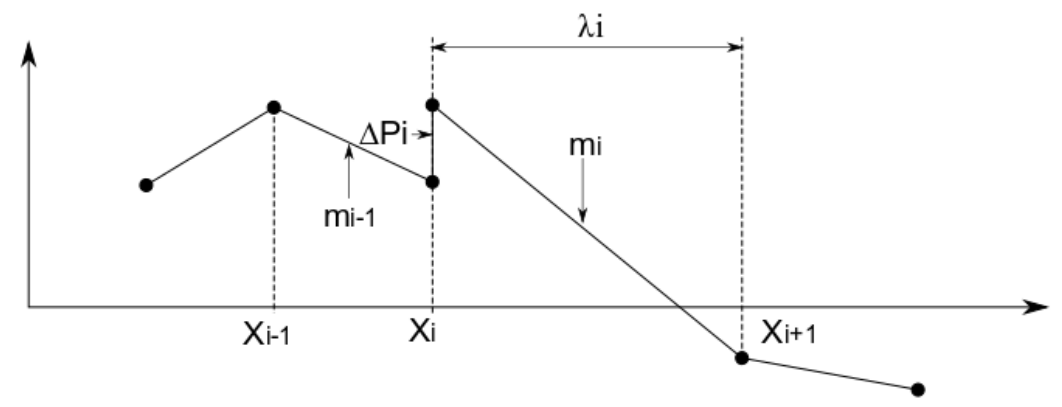

Fig. 4. Representation of Sonic Boom Signature by Waveform Parameters

The waveform parameters are defined in Eq. (13)-(15).

$$
\begin{gathered}
m_{i}=\frac{p_{\xi_{i}}}{T_{\xi_{i}}} \\
\Delta p_{i}=\sqrt{\frac{\rho_{0} a_{0}^{3}}{c_{n}^{2} A} \Delta F_{i}} \\
\lambda_{i}=T_{i+1}-T_{i}
\end{gathered}
$$

The time rate of change of these waveform parameters are the following equations.

$$
\begin{gathered}
\frac{d m_{i}}{d t}=C_{1} m_{i}^{2}+C_{2} m_{i} \\
\frac{d \Delta p_{i}}{d t}=\frac{1}{2} C_{1} \Delta p_{i}\left(m_{i}+m_{i-1}\right)+C_{2} \Delta p_{i} \\
\frac{d \lambda_{i}}{d t}=-\frac{1}{2} C_{1}\left(\Delta p_{i}+\Delta p_{i+1}\right)-C_{1} m_{i} \lambda_{i}
\end{gathered}
$$

where

$$
\begin{gathered}
C_{1}=\frac{\gamma+1}{2 \gamma} \frac{a_{0}}{p_{0} c_{n}} \\
C_{2}=\frac{1}{2}\left(\frac{3}{a_{0}} \frac{d a_{0}}{d t}+\frac{1}{\rho_{0}} \frac{d \rho_{0}}{d t}-\frac{2}{c_{n}} \frac{d c_{n}}{d t}-\frac{1}{A} \frac{d A}{d t}\right)
\end{gathered}
$$

After the calculation of $\mathrm{C}_{1}$ and $\mathrm{C}_{2}$, the ray path needs to be calculated according to Ref. [23]. When the ray path is known, the ambient properties can be calculated along the ray path. The ray tube area is then determined according to Ref. [24].

Eq. (16)-(18) can be integrated to get the following solutions.

$$
\begin{gathered}
m_{i}=\frac{m_{i}^{0} e^{C_{2} \Delta t}}{1-C_{1} m_{i}^{0} T} \\
\Delta p_{i}=\frac{\Delta p_{i}^{0} e^{C_{2} \Delta t}}{\left[\left(1-C_{1} m_{i}^{0} T\right)\left(1-C_{1} m_{i-1}^{0} T\right)\right]^{1 / 2}} \\
\lambda_{i}=\left(1-C_{1} m_{i}^{0} T\right)\left[\lambda_{i}^{0}-\frac{\Delta p_{i}^{0}}{m_{i}^{0}-m_{i-1}^{0}}\left(\sqrt{\frac{1-C_{1} m_{i-1}^{0} T}{1-C_{1} m_{i}^{0} T}}-1\right)-\frac{\Delta p_{i+1}^{0}}{m_{i}^{0}-m_{i+1}^{0}}\left(\sqrt{\frac{1-C_{1} m_{i+1}^{0} T}{1-C_{1} m_{i}^{0} T}}-1\right)\right]
\end{gathered}
$$

where

$$
T=\frac{e^{C_{2} \Delta t}-1}{C_{2}}
$$




\section{Validation of Methods}

A. Drag Calculation Method Validation

The lift and drag coefficients from GENUS (PANAIR and DATCOM) are compared with the Concorde experimental data [25, 26] at Mach 0.95 and Mach 2.0 respectively. Fig. 5a and Fig. 5b indicate that the aerodynamic coefficients from GENUS are close to the results of the experimental data, which helps to validate the methods in GENUS.

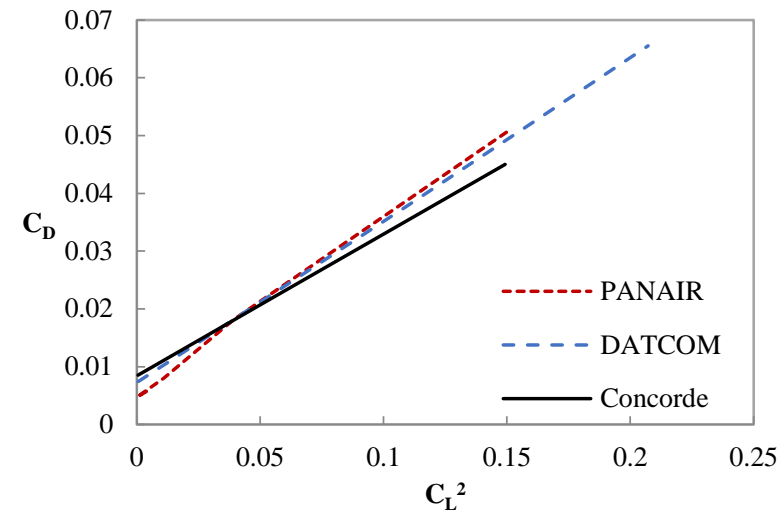

a. Aerodynamic coefficients at Mach 0.95

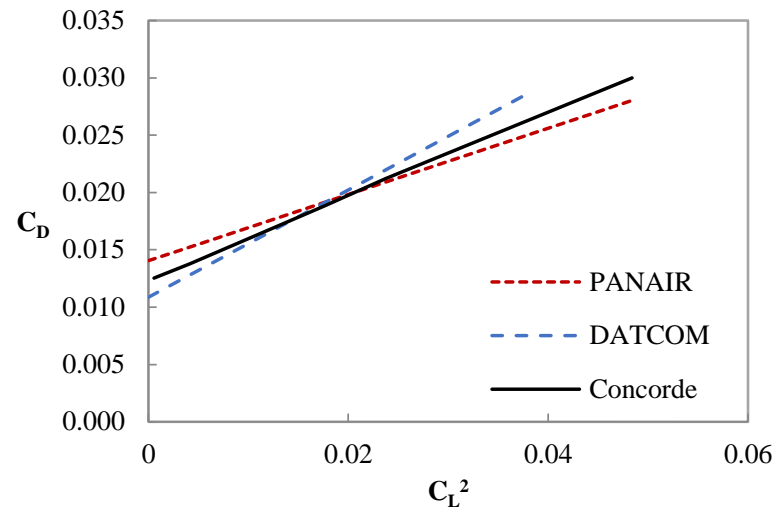

b. Aerodynamic coefficients at Mach 2.0

Fig. 5. Comparison of Concorde aerodynamic coefficients

\section{B. Boom Propagation Method Validation}

The results from the waveform parameter method are compared with the NASA PCBoom V.6. Sonic boom signatures from GENUS and PCBoom are plotted in Fig. 6. The GENUS waveform parameter method shows good coincidence with PCBoom in terms of the sonic boom intensity. There are some differences in the near-field signature time duration. These differences are tiny at ground level.

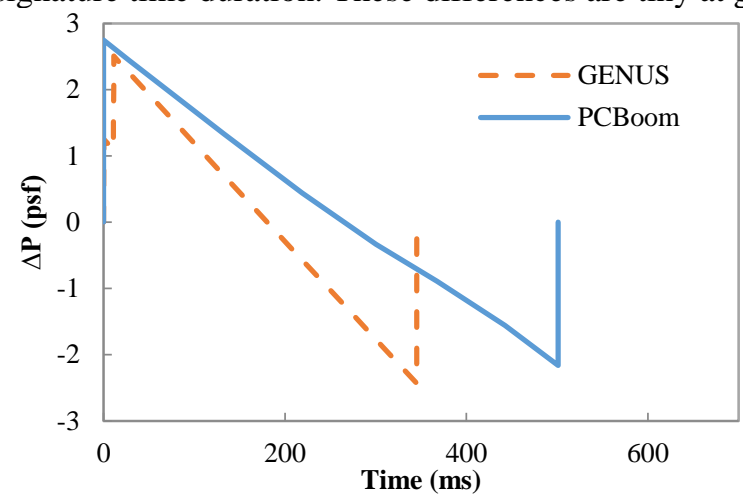

a. Sonic boom overpressure at $40 \mathrm{k}$ feet

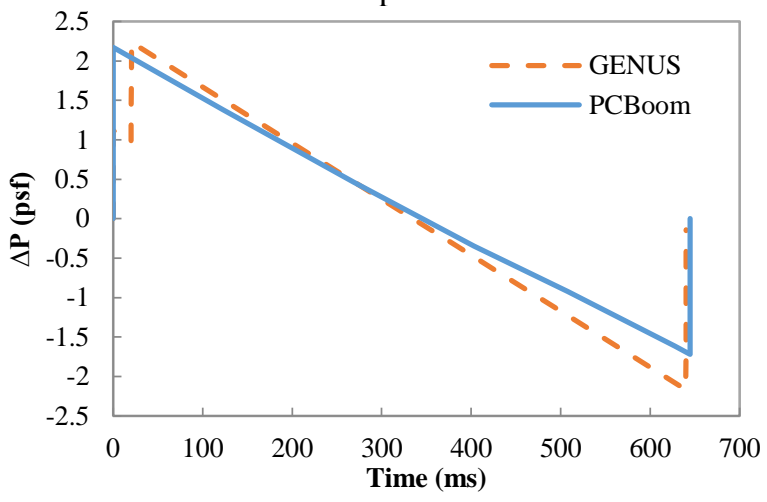

c. Sonic boom overpressure at $10 \mathrm{k}$ feet

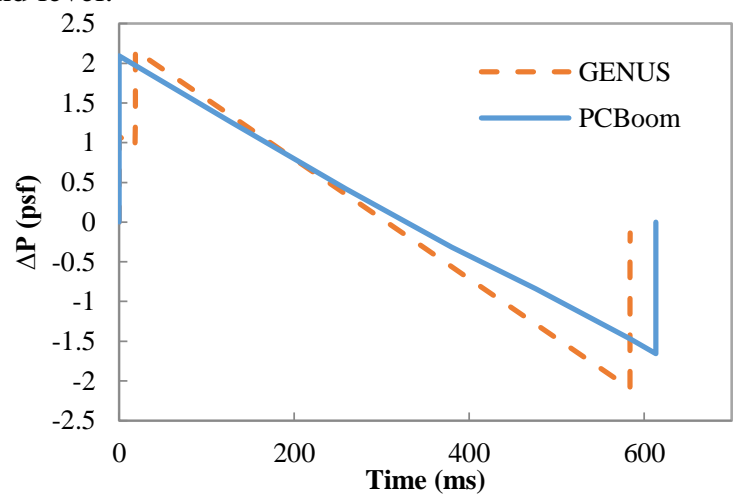

b. Sonic boom overpressure at $20 \mathrm{k}$ feet

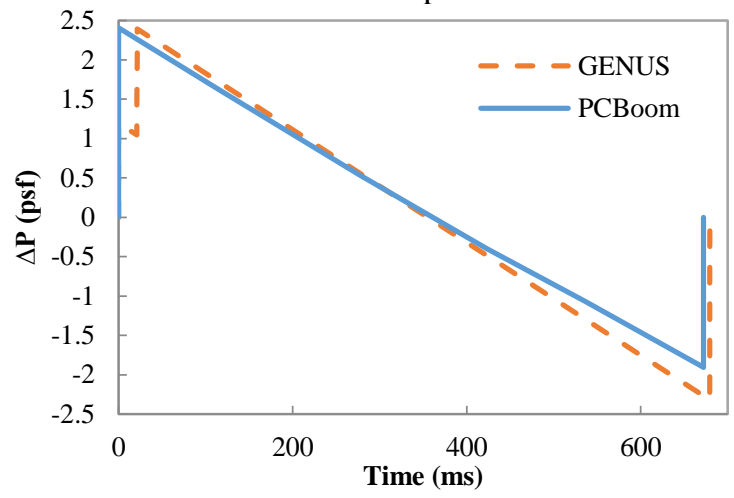

d. Sonic boom overpressure at ground

Fig. 6. Comparison of sonic boom overpressures from GENUS and PCBoom 


\section{Supersonic Business Jet Concepts Evaluation}

This section analyzes the aerodynamics and sonic boom performance of three different classes of supersonic airliners. The figures of these configurations are shown in Fig. 7. The rough geometry models are built in a multidisciplinary design analysis and optimization environment to evaluate their aerodynamic efficiency and sonic boom intensity. The geometry data of NASA QueSST X-plane comes from Ref. [28].

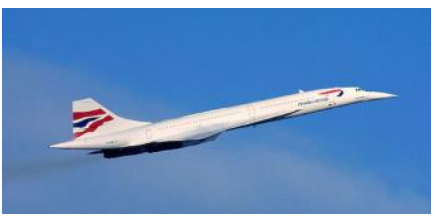

Concorde Ref. [29]

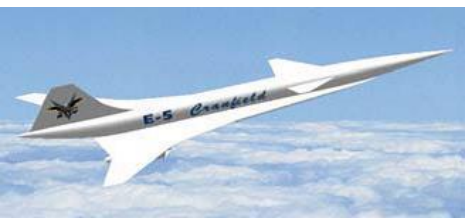

Cranfield E-5 SSBJ Ref. [30] NASA QueSST X-plane Ref. [28]

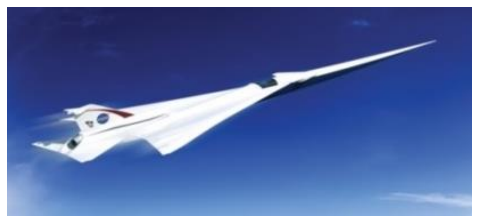

Fig. 7. Business class civil supersonic jet concepts

The mission requirements for these concepts are listed in Table 1. The table is sorted by the estimated mass. The Concorde data comes from Ref. [29]. The Cranfield E-5 data comes from Ref. [30]. The NASA QueSST X-plane data comes from Ref. [28].

Table 1. Mission requirements for SSBJs

\begin{tabular}{l|c|c|c}
\hline Requirement & Concorde & E-5 SSBJ & QueSST \\
\hline Estimated Mass $(\mathrm{kg})$ & 185,000 & 45,454 & 10,200 \\
\hline Cruise altitude $(\mathrm{m})$ & 18,000 & 15,000 & 16,760 \\
\hline Cruise Mach & 2.0 & 1.8 & 1.4 \\
\hline Target range $(\mathrm{km})$ & 8,334 & 8,334 & 100 \\
\hline Passenger number & 100 & 6 & 0 \\
\hline Crew number & 9 & 2 & 2 \\
\hline \hline
\end{tabular}

\section{A. Aerodynamic Evaluation}

The aerodynamic evaluation results are listed in Table 2. This table gives the calculated mass, gross wing area, aspect ratio, fineness ratio, surface area to volume ratio, and lift to drag ratio (L/D). We use these overall ratios to help understand the aerodynamic performance.

Table 2. Aerodynamic evaluation results of different configurations

\begin{tabular}{l|c|c|c}
\hline \hline & Concorde & E-5 SSBJ & QueSST \\
\hline Mass $(\mathrm{kg})$ & 184,667 & 45,634 & 10,272 \\
\hline Sgross $\left(\mathrm{m}^{2}\right)$ & 400.96 & 161.41 & 58.22 \\
\hline Aspect Ratio & 1.826 & 1.477 & 1.408 \\
\hline Fineness Ratio & 20.03 & 22.18 & 22.41 \\
\hline Surface Area to Volume ratio & 2.59 & 4.43 & 8.09 \\
\hline L/D at cruise & 10.77 & 9.97 & 13.02 \\
\hline \hline
\end{tabular}

Fig. 8 plots the drag polar of each configuration from $-2^{\circ}$ to $8^{\circ}$ angle of attack at cruise Mach numbers. We can see that Concorde has the largest $C_{L}\left(C_{L}=0.175\right)$ at cruise mainly because of the low cruise Mach number (Mach 1.4). QueSST X-plane has the lowest aspect ratio (1.408), thus the lowest lift curve slope. From the cruise points, we can see that the NASA QueSST X-plane is cruising near its maximum L/D point. 


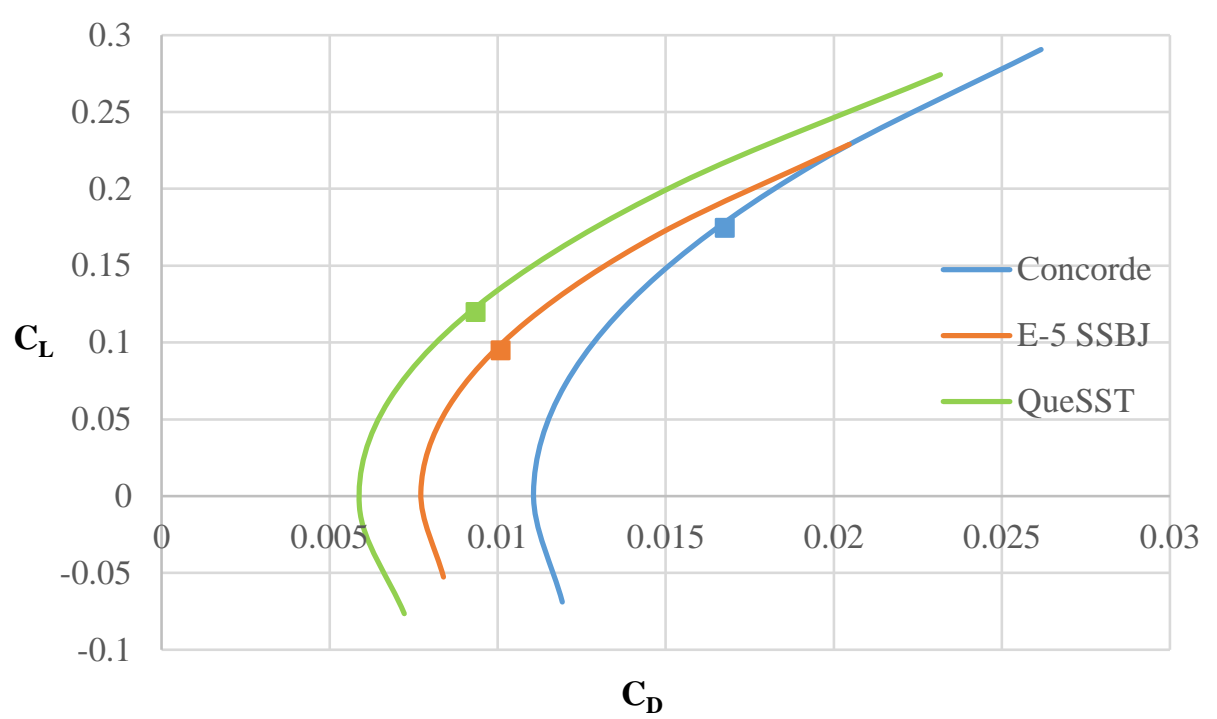

Fig. 8. Comparison of drag polar and cruise points

Another big difference we can see from Fig. 8 are the zero lift drag coefficients. The drag components of each configuration are compared in Fig. 9. The E-5 SSBJ has the biggest wave drag proportion (58.17\%). As we can see from the first derivative of volume distribution in, the Boom airliner has the largest volume change value. The NASA QueSST X-plane has the lowest value; thus the lowest wave drag proportion (11.71\%).

For the friction drag aspect, the NASA QueSST X-plane has the largest friction drag proportion (51.14\%), because it has a much larger surface area to volume ratio (8.09) than all the other configurations. The E-5 SSBJ has a low friction drag proportion (18.23\%) due to the hybrid laminar control technology [27].

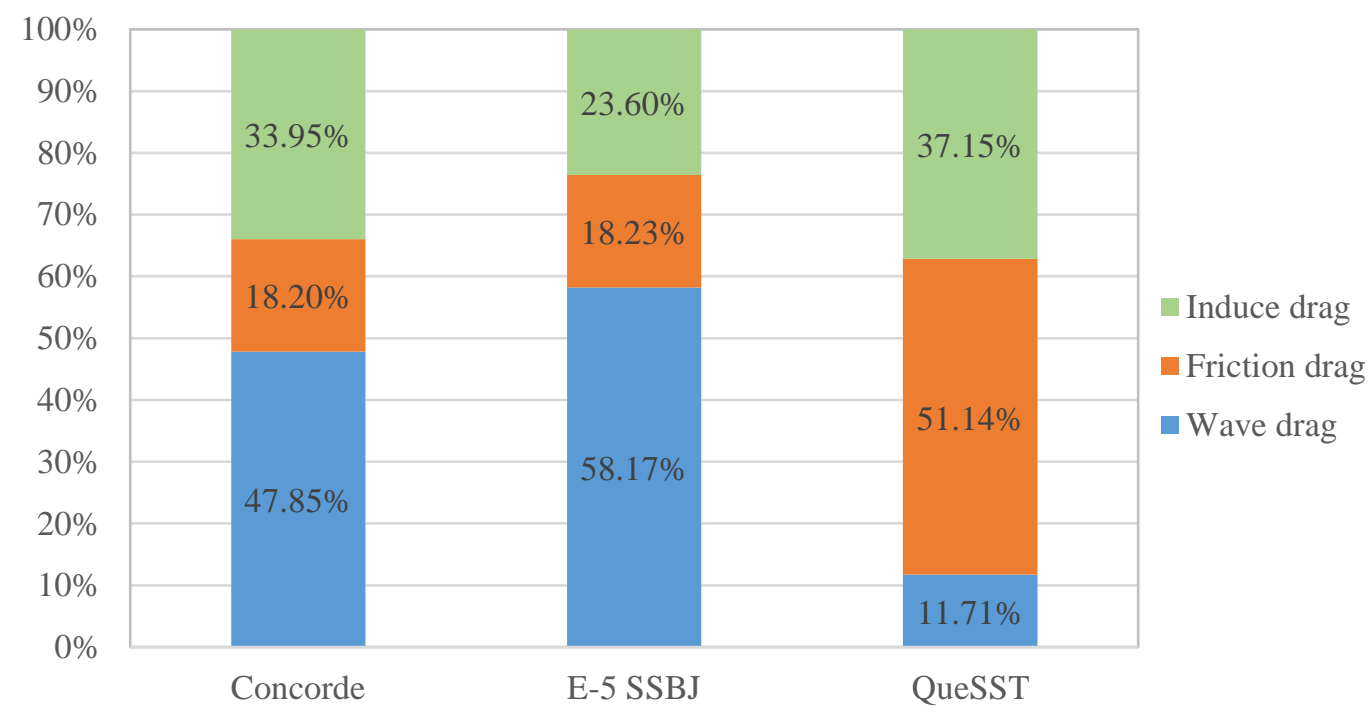

Fig. 9. Drag components of the configurations at cruise conditions 


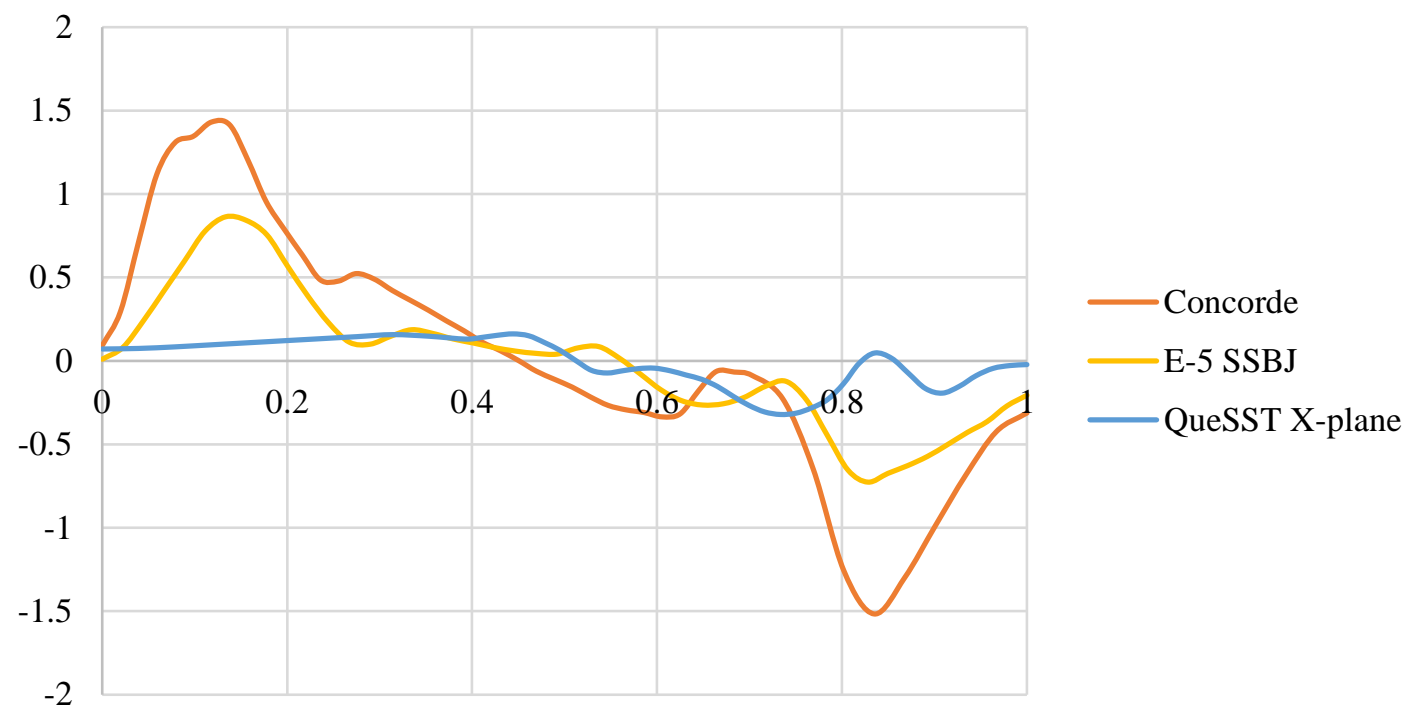

Fig. 10. Comparison of the first derivative of the volume distributions

\section{B. Sonic Boom Evaluation}

The sonic boom evaluation results are listed in Table 3. This table gives the maximum overpressure, maximum underpressure, time duration, and sonic boom intensity $(\Delta \mathrm{P})$. We use these results to help analyze the sonic boom of each configuration.

Table 3. Sonic boom evaluation results of different configurations

\begin{tabular}{l|c|c|c}
\hline \hline & Concorde & E-5 SSBJ & QueSST \\
\hline Max. overpressure $\left(\mathrm{psf}^{*}\right)$ & 3.072 & 1.324 & 0.416 \\
\hline Max. underpressure $(\mathrm{psf})$ & -3.041 & -1.693 & -0.409 \\
\hline Time duration $(\mathrm{ms})$ & 1031 & 583 & 242 \\
\hline$\Delta \mathrm{P}(\mathrm{psf})$ & 3.072 & 1.693 & 0.416 \\
\hline \hline
\end{tabular}

$* 1.0 \mathrm{psf}=47.85 \mathrm{~Pa}$

Fig. 11 to Fig. 13 give the near-field pressure and ground sonic boom signature of each configuration. For the near-field pressure, we use the F-function signature to represent the near-field pressure, because they have the same shape as indicated in Eq. (9). The F-function is decomposed to F-function due to volume and F-function due to lift, as indicated in Eq. (8), to evaluate the influence of each aspect. We can also see from Eq. (8) that the F-function due to volume is a reflection of the first derivative of volume distribution and the F-function due to lift is a refelction of the lift distribution.

The near-field and ground signatures of the Concorde are plotted in Fig. 11. The maximum sonic boom intensity is $3.072 \mathrm{psf}$. When we compare the near-field signature and the ground signature, we find that the peaks in both plots are corresponding. The $3.041 \mathrm{psf}$ underpressure is due to the end of lift distribution peak at $45.6 \mathrm{~m}$. The nose volume rate of change forms the first overpressure peak. This overpressure can be mitigated by increasing the length of the conical nose. For this class supersonic airliner, the lift effect is the domain factor for the sonic boom intensity. 


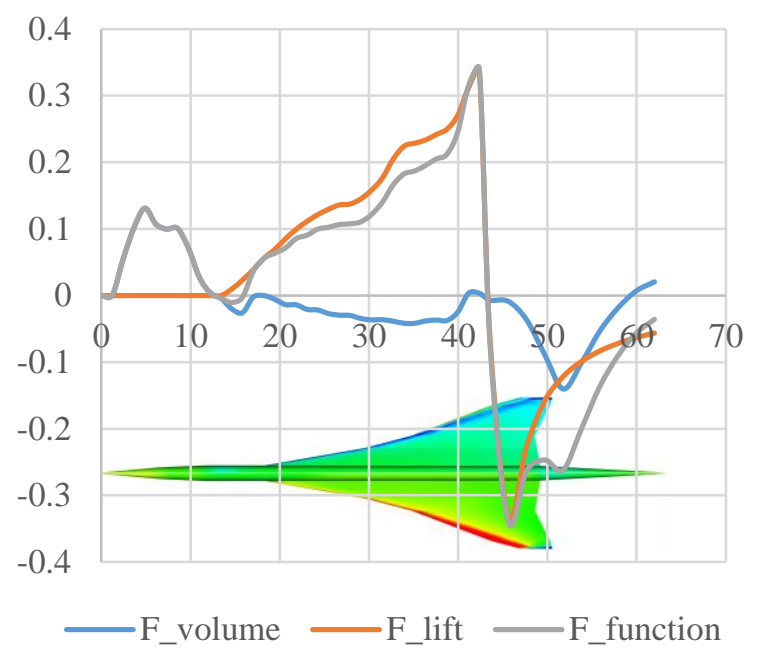

a. near-field pressure components

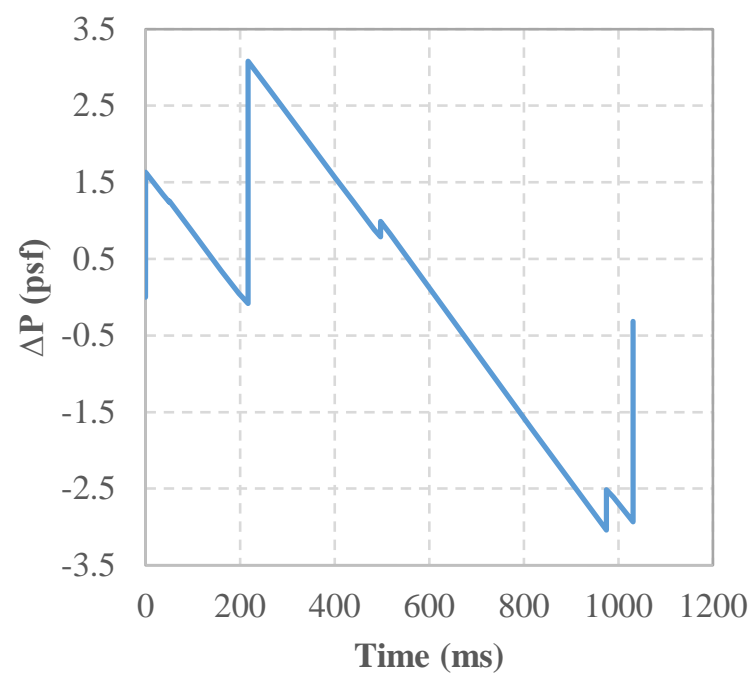

b. ground boom signature

Fig. 11. Near-field and ground signatures of Concorde

The near-field and ground signatures of Cranfield University E-5 SSBJ are plotted in Fig. 12. We can see from the ground signature that the maximum peak value comes from the aft part. In Fig. 12a, the lift distribution peak and the first derivative of volume distribution overlap to form a high peak at around $41.5 \mathrm{~m}$. The canard on top of the wing has a big influence on the lift distribution. This is because the shock wave generated by the canard forms a high-pressure zone on the wing upper surface. Thus, the wing has a negative lift at the canard zone.

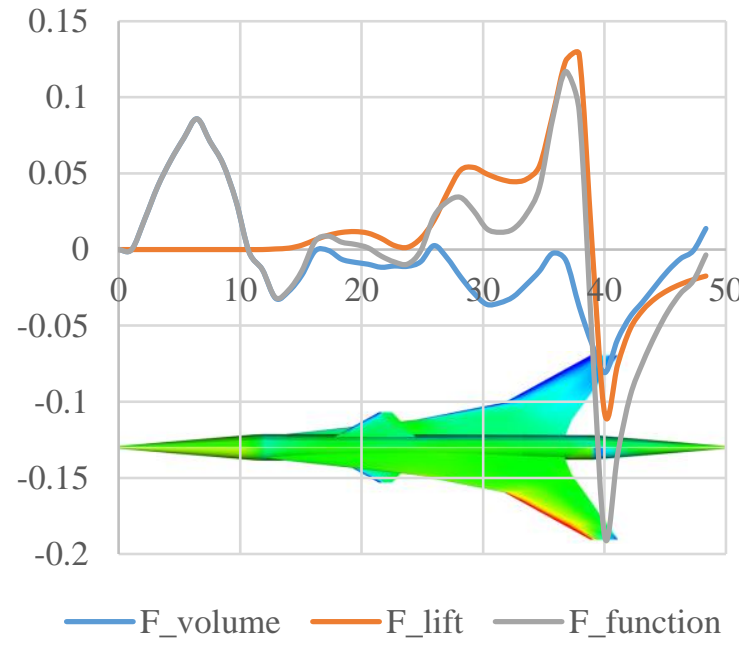

a. near-field pressure components

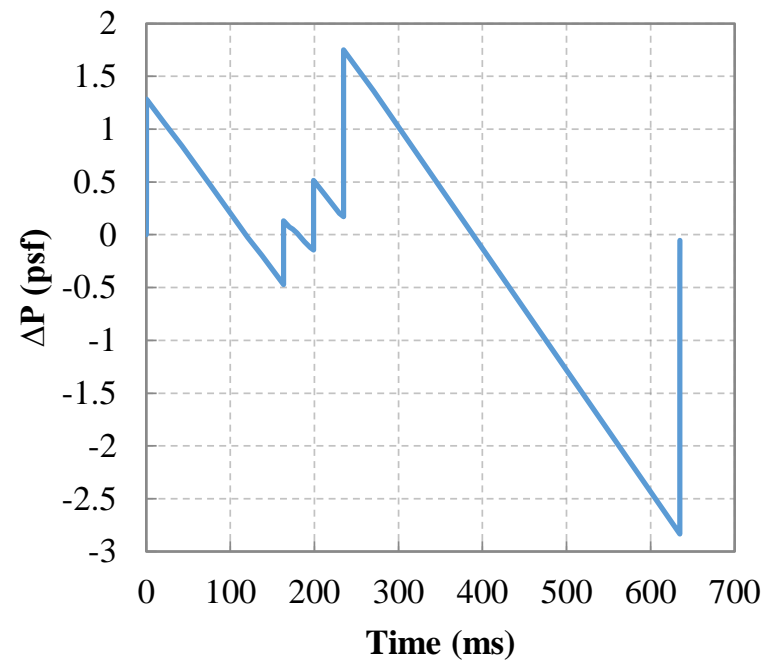

b. ground boom signature

Fig. 12. Near-field and ground signatures of Cranfield University E-5 SSBJ

The near-field and ground signatures of NASA QueSST X-plane are plotted in Fig. 13. We can see this configuration is carefully designed to mitigate sonic boom intensity. The maximum overpressure peak is almost the same height as the maximum underpressure peak. The lift distribution end peak mismatches with the volume distribution peak. 


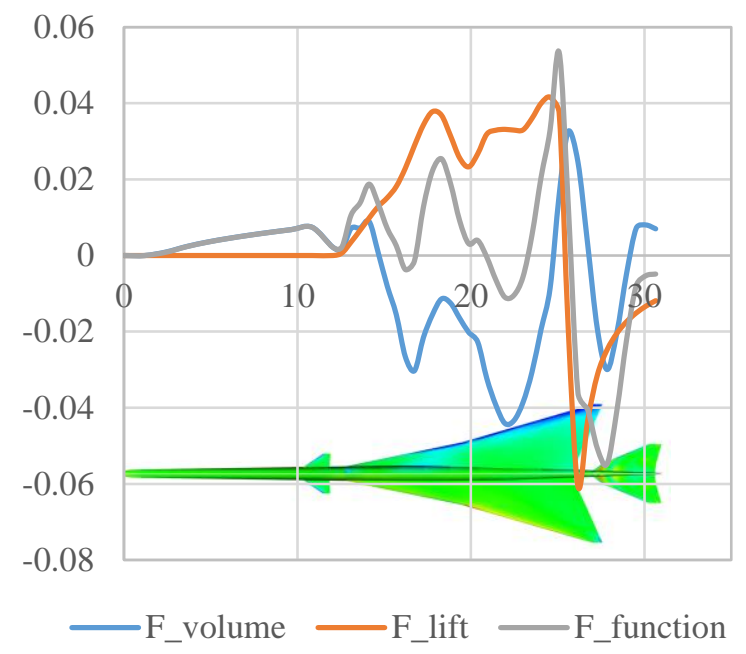

a. near-field pressure components

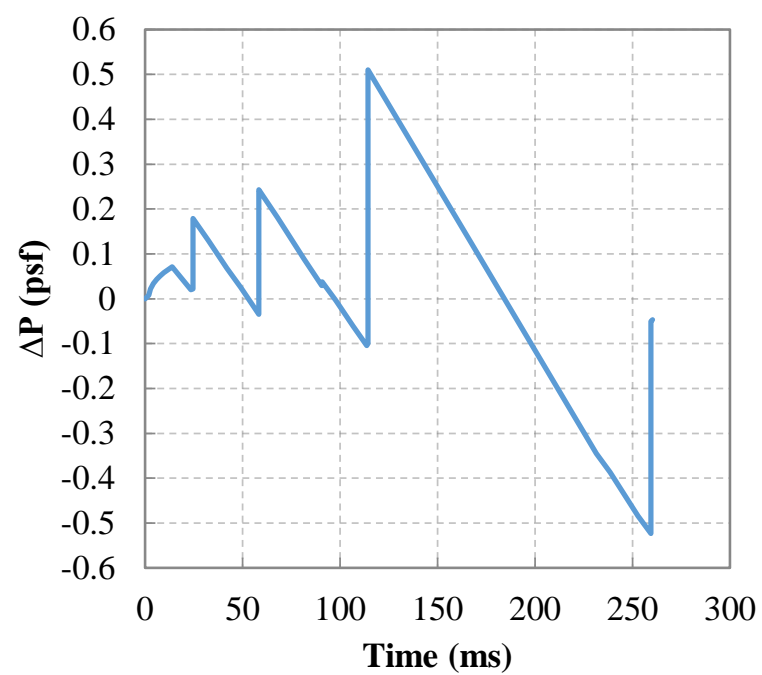

b. ground boom signature

Fig. 13. Near-field and ground signatures of NASA QueSST X-plane

\section{Overall Evaluation}

From the above analysis, we know the design point aerodynamic performance and sonic boom signature of each configuration. However, these comparisons are unfair considering their different missions. However, it is difficult to compare them under the same mission requirements. Here we plot the L/D and sonic boom intensity at different Mach numbers (Fig. 14) so that we can have a direct comparison between these configurations.

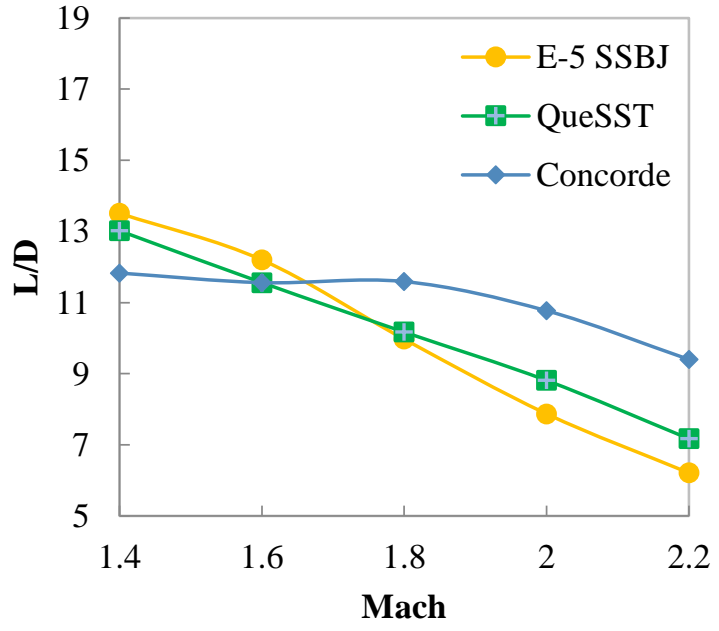

a. Lift to drag ratios

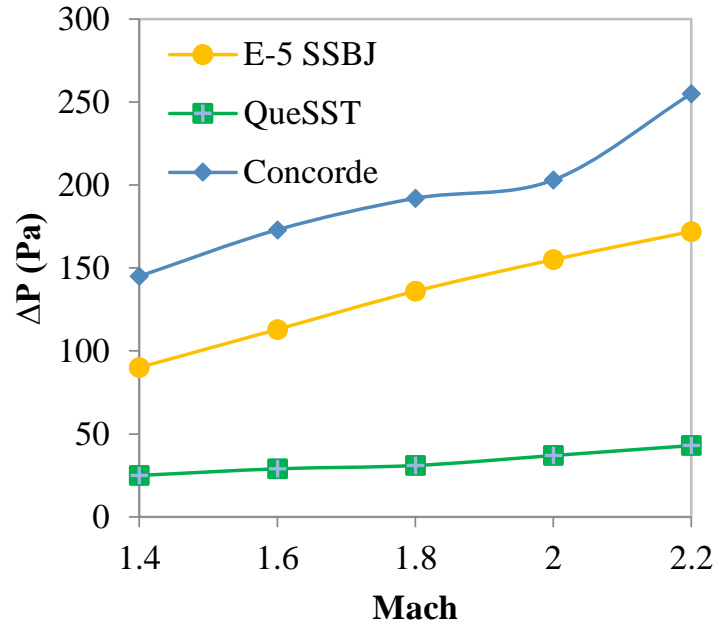

b. Sonic boom intensities

Fig. 14. Aerodynamic performance and sonic boom intensity at different Mach numbers

Through the comparison, we can find that Concorde and the NASA QueSST X-plane has a good performance at its design point, assuming they are all well designed. The sonic boom intensity is related to the size and the mass of the aircraft. The smaller and lighter the aircraft, the lower the sonic boom intensity.

\section{Conclusion and Future Work}

This paper develops aerodynamic analysis and sonic boom prediction methods for SSBJ concepts evaluation. These methods are implemented into an MDAO environment called GENUS to facilitate design optimization. These methods are validated by experimental data and the NASA PCBoom program. 
Three supersonic airliners are selected to be evaluated in the SSBJ MDAO environment. In the aerodynamic analysis, we study the aerodynamic coefficients and notice the influence of the mission requirements on the cruise point aerodynamic performance. The wave drag is directly related to the first derivative of the volume distribution. The friction drag is connected to the surface area to volume ratio and laminar flow fraction. In the sonic boom analysis, we evaluate the sonic boom intensity by studying the near-field pressure and ground signatures. We decompose the near-field pressure to volume effect and lift effect and find that the volume change rate and lift distribution can influence the sonic boom intensity individually or mutually.

Through the study, we find that the lift is the main source for the sonic boom for a Concorde class supersonic airliner. The cross-section distribution can be the main source if the geometry is not carefully designed. The smaller and lighter the aircraft, the lower the sonic boom intensity level.

Future work would include developing a low-boom low-drag configuration based on the current and previous studies. A CFD approach can be implanted as a higher-fidelity way to generate the near-field pressure.

\section{Acknowledgements}

The authors would like to thank Dr. David Sziroczak for providing assistance on the integration of the PANAIR code and thank Mr. Eduardo Sepulveda palacios for the cooperation in coding both PANAIR and EngineSim. Yicheng Sun is supported by the China Scholarship Council (CSC) to pursue his $\mathrm{PhD}$ degree in Cranfield University.

\section{References}

1. Smith, H. "A review of supersonic business jet design issues," The Aeronautical Journal Vol. 111, No. 1126, 2007, pp. 761-776. doi: https://doi.org/10.1017/S0001924000001883

2. Sun, Y., and Smith, H. "Review and prospect of supersonic business jet design," Progress in Aerospace Sciences Vol. 90, 2016, pp. 12-38.

doi: https://doi.org/10.1016/j.paerosci.2016.12.003

3. Sun, Y., and Smith, H. "Supersonic Business Jet Conceptual Design in a Multidisciplinary Design Analysis Optimization Environment," 2018 AIAA/ASCE/AHS/ASC Structures, Structural Dynamics, and Materials Conference. Kissimmee, Florida, 2018, p. 1651.

4. Smith, H., Sziroczák, D., Abbe, G. E., and Okonkwo, P. "The GENUS Aircraft Conceptual Design Environment," Proceedings of the Institution of Mechanical Engineers, Part G: Journal of Aerospace Engineering, 2018 (Accepted).

5. Tracy, R., Sturdza, P., Kroo, I., and Chase, J. "Natural laminar flow for quiet and efficient supersonic aircraft," 40th Aerospace Sciences Meeting \& Exhibit. Reno, Nevada, 2002.

6. Chan, M. K. "Supersonic aircraft optimization for minimizing drag and sonic boom," Department of Aeronautics and Astronautics. Vol. Ph.D., Stanford University, 2003.

7. Yoshimoto, M., and Uchiyama, N. "Optimization of Canard Surface Positioning of Supersonic Business Jet for Low Boom and Low Drag Design (Invited)," 33rd AIAA Fluid Dynamics Conference and Exhibit. Orlando, Florida, 2003.

8. Le, D. B., and Li, W. "A Wing Design Methodology for Low-Boom Low-Drag Conceptual Supersonic Business Jet," Virginia Space Grant Consortium Annual Research Conference. 2008.

9. Sato, K., Kumano, T., Yonezawa, M., Yamashita, H., Jeong, S., and Obayashi, S. "Low-Boom and LowDrag Optimization of the Twin Engine Version of Silent Supersonic Business Jet," Journal of Fluid Science and Technology Vol. 3, No. 4, 2008, pp. 576-585.

doi: https://doi.org/10.1299/jfst.3.576

10. Minelli, A., Salah el Din, I., Carrier, G., Zerbinati, A., and Desideri, J.-A. "Cooperation and Competition Strategies in Multi-objective Shape Optimization - Application to Low-boom/Low-drag Supersonic Business Jet," 31st AIAA Applied Aerodynamics Conference. San Diego,CA, 2013.

11. Feng, X., Li, Z., and Song, B. "Research of low boom and low drag supersonic aircraft design," Chinese Journal of Aeronautics Vol. 27, No. 3, 2014, pp. 531-541.

doi: https://doi.org/10.1016/j.cja.2014.04.004

12. Ban, N., Yamazaki, W., and Kusunose, K. "Low-Boom/Low-Drag Design Optimization of Innovative Supersonic Transport Configuration," 54th AIAA Aerospace Sciences Meeting. San Diego, California, USA, 2016. 
13. Ueno, A., Watanabe, Y., Salah El Din, I., Grenon, R., and Carrier, G. "Low Boom/Low Drag Small Size Supersonic Aircraft Design," VII European Congress on Computational Methods in Applied Sciences and Engineering (ECCOMAS Congress 2016). 2016.

14. Chudoba, B., Coleman, G., Roberts, K., Mixon, B., Mixon, B., Oza, A., and Czysz, P. "What Price Supersonic Speed? -A Design Anatomy of Supersonic Transportation - Part 1," 45th AIAA Aerospace Sciences Meeting and Exhibit. Reno, Nevada, 2007.

15. Welge, H., Nelson, C., and Bonet, J. "Supersonic Vehicle Systems for the 2020 to 2035 Timeframe," 28th AIAA Applied Aerodynamics Conference. Chicago, Illinois, 2010.

16. Maglieri, D. J. "Compilation and Review of Supersonic Business Jet Studies from 1963 through 1995," NASA/CR-2011-217144. Langley Research Center, Hampton, Virginia, 2011.

17. Saaris, G. R., Tinoco, E., Lee, J., and Rubbert, P. "A502I User's Manual-PAN AIR Technology Program for Solving Problems of Potential Flow about Arbitrary Configurations," Boeing Document. 1992.

18. Gur, O., Mason, W. H., and Schetz, J. A. "Full-configuration drag estimation," Journal of Aircraft Vol. 47, No. 4, 2010, pp. 1356-1367. doi: https://doi.org/10.2514/1.47557

19. Harris, R. V. "An analysis and correlation of aircraft wave drag," NASATM X-947. National Technical Information Service, Hampton, 1964.

20. Whitham, G. "The flow pattern of a supersonic projectile," Communications on pure and applied mathematics Vol. 5, No. 3, 1952, pp. 301-348.

doi: https://doi.org/10.1002/cpa.3160050305

21. Carlson, H. W. "Simplified sonic-boom prediction," NASA Technical Paper 1122. Langley Research Center, Hampton, Virginia, 1978.

22. Thomas, C. L. "Extrapolation of sonic boom pressure signatures by the waveform parameter method," NASA TN D-6832. Ames Research Center, Moflett Field, California, 1972.

23. Thomas, C. L. "Extrapolation of wind-tunnel sonic boom signatures without use of a Whitham F-function," NASA SP-255. NASA Ames Research Center, 1970, pp. 205-217.

24. Hayes, W. D., Haefeli, R. C., and Kulsrud, H. "Sonic boom propagation in a stratified atmosphere, with computer program," NASA CR-1299. Langley Research Center, 1969.

25. Rech, J., and Leyman, C. S. "A Case Study by Aerospatiale and British Aerospace on the Concorde," AIAA Professional Study Series. 1980.

26. Orlebar, C. The Concorde Story, 6th Edition: Osprey Publishing 1997.

27. Stocking, P. "E-5 Neutrino Supersonic Business Jet Project Executive Summery," 2005/2006 MSc Aerospace Vehicle Design. Cranfield University, 2005.

28. Bennett, J. "How NASA Wants To Build a Supersonic Plane Without the Boom," Popular Mechanics. 2016.

29. Hirschberg, M. J. Case Study by Aerospatiale and British Aerospace on the Concorde: American Institute of Aeronautics and Astronautics, 2000.

30. Smith, H. "E-5 Supersonic business jet: design specification." Cranfield University, 2005. 
2018-06-29

\section{Sonic boom and drag evaluation of supersonic jet concepts}

Sun, Yicheng

AIAA

Sun $\mathrm{Y}$, Smith $\mathrm{H}$, Sonic boom and drag evaluation of supersonic jet concepts, Proceedings of the 2018 AIAA/CEAS Aeroacoustics Conference, 25-29 June 2018, Atlanta, USA, Paper number AIAA 2018-3278

http://dx.doi.org/10.2514/6.2018-3278

Downloaded from Cranfield Library Services E-Repository 